\title{
Herdeiros do suicídio: sobre aqueles que ficam 24
}

\section{Cintia Buschinelli 25}

Gostaria de iniciar nossas reflexões a partir de um poema escrito por John Donne, poeta inglês do século XVIII:

Se um torrão de terra for levado pelas águas até o mar, a Europa ficará diminuída, Como se fosse um promontório, Como se fosse o solar de teus amigos ou o teu próprio.

A morte de qualquer homem me diminui, porque sou parte do gênero humano.

Por isso, não pergunte por quem os sinos dobram, eles dobram por ti.

Deixarei em destaque a seguinte frase: "a morte de qualquer homem me diminui, porque sou parte do gênero humano".

Tomarei agora, algo mais sobre o poema, destacando a expressão que se tornou parte da memória de tantos de nós, uma vez que ela deu nome a um romance, o mais expressivo, do grande escritor norte americano Ernst Hemingway. ${ }^{26}$ "Por quem os sinos dobram" (1940), tem como pano de fundo a Guerra Civil Espanhola, que dá visibilidade a condição humana nessa insana experiência que sobrevive e, atua em tantas circunstâncias, até os tempos de hoje.

Não custa lembrar que Hemingway participou da Guerra Civil Espanhola, como motorista de ambulância, na Cruz Vermelha, de modo que a escrita de seu livro expõe a intimidade dessa experiência que se chama Guerra. O sentimento de empatia, portanto, norteia a escrita de Hemingway em sua escrita.

Já John Donne, o poeta, não deixa sem reposta a pergunta - Por quem os sinos dobram, ele responde peremptório: eles dobram por ti.

Cada morte, mesmo aquela de alguém que não conhecemos, leva uma parte de cada um de nós, esclarece o poeta.

\footnotetext{
${ }^{24}$ Trabalho apresentado na mesa "Herdeiros do suicídio: sobre aqueles que ficam" no II Simpósio Bienal SBPSP "Fronteiras da Psicanálise: a clínica em movimento" no dia 22 de agosto de 2020.

${ }^{25}$ Membro associado da Sociedade Brasileira de Psicanálise de São Paulo.

${ }^{26}$ Hemingway usa como referência sua experiência pessoal como participante voluntário da Guerra Civil Espanhola e faz uma análise ácida, com críticas à atuação extremamente violenta das tropas de ambos os lados.

Acima de tudo o livro trata, no entanto, da condição humana. O título é referência a um poema do pastor e escritor inglês John Donne que se encontra na obra "Poems on Several Occasions" que em português chama-se "Meditações", e invoca o absurdo da guerra, mormente a guerra civil, travada entre irmãos. "Quando morre um homem, morremos todos, pois somos parte da humanidade".Em várias passagens do texto os personagens estranham e se estranham desempenhando os papéis bizarros que se viram forçados a assumir durante a guerra, e fraquejam ao ver nos inimigos seres humanos que poderiam estar de qualquer um dos lados da guerra.
} 
O que dizer da morte auto infligida, por um ser humano, não só próximo, mas alguém que contribuiu definitivamente para nossa existência, e que por desejo próprio, se é que se pode falar em desejo nessas circunstancias, desiste da vida?

Reconheço que as palavras até aqui utilizadas, não traduzem a força do fenômeno que desejo discutir.

Quando faltam as palavras, há algo que nossa compreensão ainda não atingiu. Ao escrevê-las, parece que são diminutas, superficiais pedagógicas, e não trazem à tona as emoções muitas vezes ambivalentes que tal tema possui. Mas, vamos, adiante com atenção redobrada para sentir se elas, as palavras conseguem tomam corpo.

O que se passa com aquele que viveu a experiência de perda de alguém por suicídio? Vamos construir uma imagem entre duas pessoas que seguram, cada uma delas, a ponta de um fio, com uma disparidade entre as duas figuras em relação ao seu próprio tamanho. Uma pequena e outra grande e sugestivamente forte. Mas, num átimo, a figura maior solta a corda e desaparece.

Para aquela que ficou, há uma queda para o vazio. E nos perguntamos: o que sentiu quem ficou?

Sabemos que um forte e extenso sentimento presente nas crianças é a ilusão de que o mundo existe porque elas existem.

Esse sentir descrito como uma potente força imaginária, se perde, quando aquele que segurava o fio, desaparece, levando consigo o chão que sustentava a criança. O que permanecerá em seu universo emocional é a inconfundível sensação de insuficiência.

\section{A insuficiência}

Aos herdeiros de um suicida, resta o sentimento de o quanto sua presença nas relações primordiais foi insuficiente para deter o gesto suicida.

Nesse momento, me vem à mente, aqueles que trazem, em sua vida emocional, um sentimento de vazio, que os acompanha como uma nuvem densa que cobre o sol e coloca um anteparo sensorial entre o Outro e ele. Um muro frio, defensivo se forma entre essa pessoa e seus pares. 
A propósito dessa defesa, que pode se constituir em uma espécie de anestesia, Freud (sempre ele...) em seu texto ímpar sobre Luto e Melancolia se pergunta qual o papel que a anestesia desempenha no fenômeno melancólico. Em todas suas manifestações a anestesia se manifesta na omissão ou impossibilidade da sensação de prazer e bem estar na esfera psíquica” (Freud, luto e melancolia).

\section{Função do novo outro-analista}

Nesse lugar que está vazio, da ausência primeira, onde o fio foi deixado ao léu, há muito o que se construir.

Na medida em que, como psicanalistas, participamos da reconstrução desse laço rompido, reconhecemos de imediato o sentimento que tinge de modo expressivo em tom melancólico o mundo mental e real que o paciente habita. Há um retrato nítido de que parte dele também foi diminuída, tal qual o poema descreve.

Retomo o poema para refletir como se daria a presença do outro que se dispõe a segurar a ponta da corda solta: "a morte de qualquer homem me diminui, porque sou parte do gênero humano".

O poeta propõe com firmeza a presença do sentimento de empatia e de pertencimento quando reafirma a diminuição de cada um de nós na perda de outro ser humano. É assim que o analista se encontra na presença daquele que perdeu alguém...

Não vamos esquecer que estamos todos implicados nos gestos de nossos pares, quer estejam fisicamente próximos ou a distantes.

\section{Lembranças indeléveis. A mensagem escrita em todas as superfícies: jamais me esqueça}

Um grande paradoxo é deixado para os que sobrevivem ao suicídio de pessoas próximas. Os suicidas desapareceram, mas eles deixam uma mensagem indelével de um forte desejo de jamais serem esquecidos. Uma ausência sempre presente se estabelece. 
Há algo para se pensar sobre essa presença-ausente paradoxal e permanente nos herdeiros dos suicidas, que como suponho, somos todos nós, em maior ou menor intensidade. Há uma presença na memória de quem esteve em proximidade com tais experiências, uma presença que jamais desaparece.

Também há aqueles que, como nós, gostariam de compreender algo sobre a maneira como cada subjetividade pôde absorver ou rejeitar tal experiência. Pessoas que ficam, costumam (ou poderiam) elaborar a experiência através de relatos orais ou por escrito do que viveram, temeram, imaginaram... Há com frequência um forte sentimento de que que sua presença no mundo não ofereceu sentido de pertencimento ao outro.

\section{Sem reparação}

Houve um abandono radical, que tirou imediatamente, qualquer possibilidade de reparação, um sentimento tão necessário para se lidar com os reveses das hostilidades que pertencem ao desenvolvimento psíquico de cada um de nós.

"Minha presença não fez diferença, não foi suficiente, não deu sentido ao Outro".

Tantos nãos sobre si, resultam dessa perda...

Mas, muitas vezes, pessoas que viveram tal experiência são tomadas por sentimentos de impotência, raiva e hostilidade pela vivência desse abandono radical. A ideia recorrente que também elas podem dar cabo a vida surge com frequência. Por vezes, notamos em quem teve essa experiência de perda súbita e violenta de alguém próximo, a presença de uma ansiedade dispersiva, uma angústia espalhada sem direção.

No relato do suicídio do pai, expresso em palavras telegráficas, uma forma rápida de enviar a mensagem ao analista, a paciente não se detém no assunto, e procura demonstrar uma naturalidade-não natural, ao trazer um assunto tão difícil de se colocar em palavras. 
Estes são alguns dos inúmeros sentimentos e interrogações que se desencadeiam a partir de uma experiência como essa. Para finalizar, gostaria de trazer para nossa reflexão, a experiência da poetisa Sylvia Plath ${ }^{27}$ :

A perda de seu pai ainda na infância marcou profundamente sua vida e sua obra. Otto, pai de Sylvia não procurou tratamento para doença curável, quando se encontrava doente. Um suicídio lento, podemos pensar ... Estaria Sylvia emocionalmente situada no universo dos herdeiros do suicídio? nos cabe perguntar.

"Só deus sabe que ferida a morte de seu pai lhe causara na infância, mas ao longo dos anos essa ferida foi se transformando na convicção de que ser um adulto significava ser um sobrevivente”. (Alvarez, O Deus Selvagem). Para encerrar, um trecho de um poema de Sylvia Plath:

\section{Gulliver}

Sobre seu corpo as nuvens passam

Altas, altas e geladas

E um tanto finas, como se

Flutuassem num vidro invisível.

Diferentes dos cisnes,

Não têm reflexos;

Diferentes de você,

Sem cordas para te prender.

Tudo bem, tudo azul. Diferentes de você -

${ }^{27}$ Sylvia Plath (Boston, 27 de outubro de 1932 - Londres, 11 de fevereiro de 1963) foi uma poeta, romancista e contista norte-americana. 


\section{Patologização e Medicalização das crianças com “Dores da Alma” 28}

\section{Leonardo Posternak 29}

A expressão DORES DA ALMA do título, foi extraída de um texto importante e corajoso de Roudinesco, no qual a autora faz uma crítica aos profissionais que colaboram com a patologização e medicalização (em excesso e muitas vezes sem critério) das crianças. Ela afirma que agindo dessa maneira, roubam dos pacientes (adultos e crianças) o tempo necessário para elaborar e superar a comoção produzida por situações traumáticas.

A tentativa de "curar" com medicamentos, a tristeza, a agressividade, a agitação, as insônias, as dores de cabeça e barriga sem patologia de base, os transtornos de aprendizagem, as inapetências não orgânicas, se dá em virtude do não reconhecimento desses quadros como um sintoma de outras patologias, ou seja se toma a" febre como a doença a ser tratada”, o que em todo caso é uma conduta imprópria, inocente e incompleta.

$\mathrm{Na}$ atualidade, existe uma triste constatação, perdemos o direito de estar “tristes" sob o risco de ser diagnosticados como portadores de depressão.

Com a medicação se atropela o tempo psíquico que o sujeito necessita para recuperar sua capacidade de simbolizar.

Para isso, na formação médica deveria ter uma brisa de subjetividade em instituições lotadas de objetividade e da procura incessante de evidências.

As famílias, os médicos e os professores, de alguma forma estão envolvidos nesta situação de "cura química rápida”. Mas é necessário entender que todos estão preocupados, frustrados, confusos e muitas vezes incomodados pela situação.

O que acaba acontecendo e que não tendo uma visão integradora se acaba ocluindo as causas dos sintomas, na tentativa de colocar a criança "na redoma encantada da normalidade estatística". Até que surge a pergunta: "O que é a normalidade?”. Nesse momento fica tudo bagunçado e sem resposta.

\footnotetext{
${ }_{28}$ Trabalho apresentado na mesa "Depressão: expressões na infância” no II Simpósio Bienal SBPSP "Fronteiras da Psicanálise: a clínica em movimento" no dia 22 de agosto de 2020.

29 Trabalha em clínica pediátrica particular e no Hospital Israelita Albert Einstein; é autor de $O$ direito à verdade (Prêmio Jabuti 2003).
} 
O outro aspecto educativo desta problemática é o abuso na medicina da utilização abusiva de siglas, como as que se seguem:

- TDA (transtorno de déficit de atenção)

- TDAH (transtorno de déficit de atenção com hiperatividade)

- DNPM (desenvolvimento neuro -"pisco"-motor)

Observamos frases inteiras travestidas em siglas.

Marcuse, afirmou que a sigla não é a demonstração de preguiça de quem escreve, pelo contrário o autor disse taxativamente que a sigla tem a função de denegar, ou de esconder a realidade da qual se opina ou se escreve.

Marcuse menciona a sigla ONU, que é a Organização das Nações Unidas, que todo mundo sabe que no prédio que funciona em N.Y., não existe nenhuma organização, e muito menos união entre as nações que a integram!!

Em pediatria, a sigla DNPM (que significa Desenvolvimento neuro-psicomotor) esconde uma nítida falácia, a letra $\mathrm{P}$ que significa Psico na sigla, dificilmente entra no exame semiológico feita em pediatria. No paciente infantil só se examina o desenvolvimento neuro-motor.

Vou tentar demostrar que na patologização de alguns comportamentos infantis, hoje só se percebe um acirramento, tudo começou há muito tempo...

Em 1798 (!!) aparece um pequeno texto precursor do estado mental do TDAH. O autor e um neurologista, e o título "Uma pesquisa sobre a natureza e origem da perturbação". As crianças dessa época tinham sorte, posto que não existiam fármacos para elas, mas por outro lado eram sometidas a uma educação dura e traumática.

Em 1845, Hoffman médico alemão escreve um poema deturpador "Fidgety Philip" que descreve um menino hiperativo. $\mathrm{O}$ autor se solidariza com o sofrimento dos pais, sem mencionar como se deveria ajudar o menino.

Em 1902, um pediatra famoso, Still (uma artrite leva seu nome), descreve 43 crianças sem controle e com defeitos "mórbidos e amorais", e acrescentava o título de "depravados".

Em 1937 o Dr. Charles Bradley, utilizou a benzedrina em crianças com "distúrbios neurológicos e de comportamento".

Em 1944, Leandro Pannizon sintetiza o Metilfenidato," CASUALMENTE" durante os anos em que a conduta proeminente era a intervenção psicológica como o melhor tratamento desses distúrbios de comportamento. 
A partir de 1972, já formado assisti ao aparecimento de tantos outros quadros sem fundamento clínico nem laboratorial aos quais se tentou medicar. Junto a muitos outros médicos lutei contra esses despropósitos. Vejam a lista seguinte da "PSEUDOENFERMIDADES" na tentativa de usar medicação:

a) Disfunção Cerebral Mínima: inexistente. Rapidamente esquecida.

b) TCPE (Transtorno Comportamental Pós Encefálico). Nenhum paciente tinha encefalite.

c) DISRITMIA: diagnóstico falso do EEG. Não existe o padrão normal de EEG

d) TDAH: Reaparece o METILFENIDATO.

Essas eventuais tentativas medicamentosas aparecem sem estar baseadas em evidências científicas e sem olhar para o sujeito!! Por outro lado, as anfetaminas têm efeitos colaterais perigosos.

Acabei de ler o excelente livro publicado pela Ágalma e coordenado por Inés Catão intitulado "Mal-estar na Infância e medicalização do sofrimento: quando a brincadeira fica sem graça."

No prefácio Inês com muita sensibilidade relata o seguinte diálogo com um paciente:

"Por que você não gosta de tomar RITALINA?". Ela pergunta:

"Porque deixa a brincadeira sem graça". Responde ele.

A psicanalista, a partir da resposta do menino de 10 anos, afirma que ela não (eu acrescento ninguém) seja capaz de descrever esse efeito colateral da droga que não consta na bula!

Neste livro, Angela Vorcaro indica a urgência em solucionar a tentativa Medicamentosa em situações psíquicas que aparecem como sintomas na infância, com o intuito de aliviar as angústias das crianças (e também da família), se cria uma situação biunívoca imediata: entre o malestar psíquico e o apaziguamento da criança pela medicação.

A medicação age como um "amortecedor" da criança, que perde sua expressão corporal e seu comportamento disfuncional (o sintoma) que são recursos com os quais ela faz um chamamento para obter ajuda.

Ao atrapalhar a sua vida simbólica, se gera maior sofrimento, por impedir o trabalho psíquico de elaboração do sintoma. 
Por outro lado, devemos lembrar que por trás de uma criança que se apresenta como "agitada" ou "desatenta, sempre a uma chance de existir algum tipo de confinamento urbano (mais evidente na quarentena), falta de brincadeiras de rua (perigoso), as agendas infantis de" executivo" e a impossibilidade de descarregar sua enorme energia. Muitos distúrbios aparecem como "depressão".

Em outro capítulo, Julieta Jerusalinsky e outros, com muita sutileza e profundidade citam as diferenças entre os joelhos das crianças de décadas atrás e os joelhos atuais. Antes se viam joelhos sempre machucados, cortados, ralados que não conseguiam cicatrizar por logo receber outro machucado. Eram joelhos calosos, curtidos por muitas brincadeiras corporais. Tudo feito com muito grito e muita correria...

Hoje as crianças têm joelhos imaculados, são mais quietas, ficam muito tempo sentadas ante uma tela. Elas não devem gostar de serem rotuladas com as famosas siglas (TDAH), nem de ser apaziguadas quimicamente. E o mais importante: não devem gostar de serem nomeadas" transtornadas ou transtornadoras."

Entremeado com todo este problema temos que considerar os percalços de nossa formação cartesiana. Descartes fez, duas afirmações trágicas, a primeira é que a medicina deveria ser uma tarefa exclusivamente objetiva, sem traços de subjetividade!

A segunda é que a mente estaria fora do corpo, criando assim o corte entre a psique e o corpo, o que continua presente na medicina até hoje.

A luta é árdua, mais vale a pena de ser lutada.

Está em jogo muitas das coisas que são discutidas nestas jornadas. Com que contamos?

- Com a nossa liberdade

- Com a ética

- Com a aceitação do não saber

- Com a resolução do paradoxo onipotência/impotência.

Se não entramos nesse combate, se reproduzirão as tristes estadísticas desta última década, mostrando dados da OMS e do DATASUS que são amedrontadores: 


\section{Os pediatras identificam apenas de 15 a $20 \%$ dos transtornos}

psicoemocionais das crianças que atendem ou seja mais de $70 \%$ ficam sem diagnóstico.

Com respeito a ética, o filósofo espanhol Savater disse que "a ética não é um receituário de respostas moralizantes. Acredita que a ética não serve para solucionar algum debate, embora a sua função seja colaborar para iniciar todos os debates".

Para falar da liberdade me apoio em Otavio Paz que disse:

"A liberdade é um movimento da nossa consciência que nos leva em determinados momentos a pronunciar dois monossílabos: "SIM" ou "NÃO ", palavras que na sua brevidade, desenham o sinal contraditório da natureza humana".

Finalizo meu trabalho com uma referência ao olhar e a escuta atenta do médico. Foi dita por um excelente médico clínico espanhol, o Dr. Gregorio Marañao há mais de 100 anos: (continua moderníssima!) “O melhor invento para a medicina, foi a cadeira, que permite que 2 pessoas (um médico e o seu paciente), sentem, se olhem e conversem".

É disso que se trata.

\section{Referências}

Catão, Inês. Mal-estar na infância e medicalização do sofrimento. Quando a brincadeira fica sem graça. Ágalma, 2020.

Dueñas, Gabriela. La patologización de la infancia. Niños o Sindromes, Noveduc, 2014.

Meira, Ana Maria (Org.). Novos Sintomas. Ágalma, 2003.

Posternak, Leonardo. Educar filhos - entre a renúncia e a urgência.

Ágora, 2020.

Untoiglich, Gisela. En la infancia los diagnosticados se escriben con lápiz. Noveduc, 2013. 